\title{
Unmet Need for Modern Family Planning and associated factors among Women Attending HIV Care Services at Rural Area Public Health facilities in South Gondar, Ethiopia.
}

\author{
Mulgeta Adugna \\ University of Gondar Referral and specialized Hospital \\ Moges Muluneh Boke ( $\nabla$ mogelove75@gmail.com ) \\ University of Gondar College of Medicine and Health Sciences https://orcid.org/0000-0001-7940-2691 \\ Amare Tariku \\ University of Gondar College of Medicine and Health Sciences
}

\section{Research}

Keywords: Unmet need, contraception, HIV-positive women, ART, South Gondar, Ethiopia.

Posted Date: December 21st, 2020

DOI: https://doi.org/10.21203/rs.3.rs-130769/v1

License: (9) This work is licensed under a Creative Commons Attribution 4.0 International License. Read Full License 


\section{Abstract}

Introduction: To achieve the elimination of mother to child transmission of the human immunodeficiency virus (HIV), preventing unintended pregnancy and reducing the high unmet need for family planning among HIV positive women was crucial. Despite being crucial little has been known on the unmet need for family planning and its determinants among women living with HIV in the rural area. Therefore, this study aimed to assess the prevalence of unmet need for modern family planning and its determinants among women Attending HIV Care Services at rural Public Health Facilities.

Methods: An institution-based cross-sectional study was conducted from March to April 2020 in rural South Gondar. A total of 931 respondents were included in the study. To recruit respondents a multi-stage sampling technique was used. The data were collected using a pretested and semi-structured questionnaire. Data were entered by Epi data version 4.6 and exported to Stata version 14 for analysis. Variables with a $p$-value $<0.2$ in the bivariable logistic regression model were fitted to the multivariable logistic regression model. Adjusted Odds ratio with $95 \% \mathrm{Cl}$ was computed and variables with P-value $<0.05$ in the multivariable analysis were taken as significant determinants.

Results: The prevalence of unmet need for family planning was $25.67 \%$ with $95 \% \mathrm{Cl}$ (22.9628.58). Age group (3549) $(\mathrm{AOR}=6.5,95 \% \mathrm{Cl}(2.86,14.66))$, education status $(912)(\mathrm{AOR}=0.25,95 \% \mathrm{Cl}(0.10,0.61))$, history of ever use Contraception $(A O R=3.9,95 \% \mathrm{Cl}(2.28,6.67))$, having five and above parity $(A O R=5.1,95 \% \mathrm{Cl}(2.08,12.43))$ and not Counselling for contraception $(A O R=4.2,95 \mathrm{Cl},(1.91,9.37))$ were determinant for unmet need of contraception among HIV positive women in South Gondar.

Conclusion: prevalence of unmet need for family planning was high. It was mainly

Influenced by last reproductive age group (35-49)), education (9-12), having no experience of contraception use, having five and above parity, and no counseling for contraception. Therefore, family planning programs need to focus on old (35-49) reproductive age women, and multi-para women.

\section{Introduction}

Contraceptive use increased in many parts of the world, especially in Asia and Latin America(1). Of 1.9 billion reproductiveage women worldwide, 1.1 billion need family planning; of these, 842 million are using contraceptive methods, and 270 million have an unmet need for contraception $(1,2)$, but in developing countries, 214 million women of reproductive age who want to avoid pregnancy were not using a modern contraceptive method(1, 2). In Latin America, Asia, and Africa, 10.7\%, $10.2 \%, 24.2 \%$, of women of reproductive age have an unmet need for modern contraception respectively $(1,3)$. More than one in ten married or in-union women worldwide have an unmet need for family planning and In Africa, one in five women has an unmet need for family planning $(1,2)$.In Ethiopia based on the general population survey among reproductive age (15-49), the prevalence of unmet need for family planning was $22 \%$ among reproductive age group, lowest in Addis Ababa (11\%), highest in the Oromia region (29\%), and $17 \%$ in Amhara region (4).

Contraception is a highly cost-effective HIV prevention strategy than the provision of ART and prophylaxis (5). Contraceptive use averts about 230 million births every year globally (6). Spacing children can reduce mortality among under-fives by $10 \%$ and among pregnant mothers by 32\% (6). Approximately 120000 HIV-positive births per year would be averted if the family planning needs of all HIV-positive women in sub-Saharan Africa could be met (7).

In Ethiopia 2,728 unintended HIV-positive births annually are averted by using contraception(8), and decrease an estimated $20 \%-30 \%$ of newborn HIV infections will be averted if unintended pregnancies are prevented among HIV-positive women by using modern family planning (8). From 21 focus African countries, the Vertical transmission rate exceeding 17\% in Ethiopia (9). 
One of the most effective approaches to prevent mother to child HIV transmission is decreasing the rate of unintended pregnancy and decreased the unmet need for family planning $(10,11)$. The concern of effective use of family planning (FP) can help couples achieve the desired number of children they want, prevent the number of unwanted pregnancies and abortion, reduce the risks of sexually transmitted infections (STIS), improvement in maternal and child health, and reducing infant HIV infections and the number of children needing HIV treatment and support (12-14).

Women living with HIV (WLHIV) experience high rates of unmet for modern family planning, maternal death, abortion, and unintended pregnancy $(12,15-23)$.

Several reasons for the high prevalence of unmet need for modern family planning among HIV positive reproductive women include limited choice of methods(23); limited access to services (23), particularly among young, fear or experience of sideeffects; cultural or religious opposition (12,22-24); poor quality of available services; users' and providers' bias against some methods $(22,23)$; desire for more children $(12,22)$ and gender-based barriers to accessing services $(12,22-24)$.

The World Health Organization's (WHO) four-pronged strategy for prevention of mother-to-child HIV transmission (PMTCT) includes the Prevention of unintended pregnancies among HIV-positive women through FP and reduced the unmet need for family planning among women living with HIV infection is a highly cost-effective HIV prevention strategy (25). Ethiopia also adopts the WHO four-prong strategies to eliminate vertical transmission of HIV and national adolescent and youth health strategy to address the health of reproductive age women $(26,27)$.

However, the prevalence of unmet need for modern family planning among Ethiopian married women living with HIV was high $(19,21,28)$. However, to estimate the prevalence of unmet need for modern family planning single study area in the referral hospitals is not enough. Little is known about the prevalence and associated factors of unmet need for family planning among reproductive-age women living with HIV at the rural general hospital, primary hospital and health center levels in the study area. Therefore, the objective of the study is to determine the prevalence and contributing factors of the unmet need for modern family planning among HIV-positive reproductive-age women in the rural area general hospital, primary hospital and health centers.

\section{Methods}

\section{Study design and period}

An institutional-based cross-sectional study was conducted among HIV-Positive Women attending HIV Care Service in the Rural South Gondar zone from March to April 2020.

\section{Study area}

The research was conducted in rural South Gondar Zone which is found in Amhara regional state located at $664 \mathrm{~km}$ from the capital city Addis Ababa. Based on the 2007 Census conducted by the Central Statistical Agency of Ethiopia, the South Gondar zone had a total population of 2,051,738 and a natural increment of $16 \%$ over the 1994 census, of which 1,041,061 are men and 1,010,677 women (29). In the South Gondar zone, there were 96 health centers, of those 07 primary hospitals and 01 general hospitals available, but only 32 health facilities provide ART services. Based on the 2019 South Gondar HIV /AIDS prevention and control office report 10,829 people current on ART, from the total current on ART 6781 were reproductive age women (30).

\section{Population}

All HIV Positive reproductive age married/union women (15-49 years) attending ART clinics of the health facilities in the South Gondar during the study period were considered as the study population. Seriously ill during the data collection period and infecund reproductive-age women were excluded from the study.

\section{Sample size determination and sampling procedure}


The sample size was determined by using a single population proportion formula by considering assumptions $95 \%$ of $\mathrm{Cl}, 4 \%$ of marginal error, $5 \%$ of non-response rate, and the prevalence of unmet need for contraception among HIV positive women was $25.1 \%$ (19), and design effect 2. Finally, the required sample size was 937.

Multi-stage sampling methods were employed to select the study population. From a total of Thirty-two ART service provide health facilities, Six Health facilities were selected by lottery method. Then the estimated sample size is proportionally allocated to health facilities based on the previous month's clients' flow number. Finally, study participants were selected by systematic random sampling method with a k interval of two.

\section{Operational definition}

\section{Unmet need for modern family planning}

The sum of the proportion of a woman who is married/ sexual union and fecund women do not want any more children or want to postpone pregnancy for at least two years, but she is not using a contraceptive method and currently pregnant or postpartum amenorrhoeic women being pregnant earlier than she desired or do not want a child at all, but don't use the contraceptive method during conception $(4,31)$.

\section{Unmet need for limiting}

the sum of the proportion of women who is married/sexual union and fecund who do not want any more children and currently pregnant or postpartum amenorrheic who do not want a child at all but she is not using a contraceptive (4).

\section{Unmet need for spacing}

the sum of the proportion of women who is married/sexual union and fecund women who want to postpone pregnancy for at least two years and Current pregnant or postpartum amenorrhoeic women being pregnant earlier than she desired but, don't use a modern contraceptive method $(4,31)$.

\section{Knowledge of PMTCT}

defined as knowing of transmission from mother to child during any of the pregnancy, delivery, and breastfeeding(20).

\section{Data collection tool and procedure}

A structured interviewer-administered questionnaire was used for data collection. The questionnaire was developed from Ethiopia demographic health survey and by reviewing national and international literature. The data collection instrument was prepared in English. Then the English version of the questionnaire was translated first to Amharic and back to English to ensure its consistency. The questionnaire has information on socio-demographic characteristics, reproductive related factors, and HIV care-related factors.

Data was collected by 14 health professionals; three BSc and two diploma female nurses, 2 BSc, and 5 clinical midwifery and two health officers who were working in the ART clinics and post-natal follow-up clinics of the respected hospitals and health centers. In addition to the principal investigator, 03 BSc nurse supervisors were assigned to supervise the data collectors and to check for completeness and consistency of a questionnaire.

\section{Data quality control}

The quality of data was assured through translation, and retranslation of the questionnaire as well as pretesting on $5 \%$ of the sample was done at Maraki health center for relevant amendment. Onsite training was given for data collectors and supervisors before the data collection starting on the objective of the research, data collection procedure, and ethical issues. The supervisors and principal investigator closely followed the day-to-day data collection process and ensure the completeness and consistency of the collected questionnaire. 


\section{Data management and analysis}

The data were entered using Epi Data version 4.6 by the principal investigator and then exported to Stata version 14 for cleaning and analyzing. Descriptive statistics were used to describe the socio-demographic characteristics of the respondents, reproductive related factors, individual-related factors and the prevalence of unmet need for contraception. The association between the unmet need for family planning with predictors was checked by chi-square. Binary logistic regression was used to identify the factor associated with the independent variable. The variables of the $p$-value $<0.2$ in the bivariable logistic regression model were fitted to a multivariable logistic regression model to identify factors associated with unmet need for family planning. Adjusted Odd ratio with $95 \% \mathrm{Cl}$ was computed and variables with P-value $<0.05$ in the multivariable analysis were taken as significant determinants. Hosmer- Lemeshow test was checked and the $p$-value was 0.1058 and multicollinearity was checked and the result was a mean VIF 1.25.

\section{Results}

\section{Socio-Demographic Characteristics of the Study Participants}

From a total of 937 HIV positive reproductive age women in the selected health centers and hospitals, 931 study participants were included in the study, with a response rate of $99.4 \%$. The mean age of the respondents was 31.3 years with (SD of \pm 6.5) years. The majority $886(95.17 \%)$ of the respondents were Orthodox Christian followers. Four hundred four (43.39\%) respondents were reported that they haven't attended formal education, while 301(32.33) \% were attended only primary level education. The majority 402(43.18\%) of respondents' partners had no formal education. Of the study participants, 154(16.54\%) was civil servant employment while 321(34.48\%) Were housewife. Three hundred thirty-five (35.98\%) of household wealth were poor (Table 1). 
Table 1

Sociodemographic characteristics of women in reproductive age on ART in South Gondar Zone, 2020

\begin{tabular}{|c|c|c|c|}
\hline Variables & categories & Frequency & Percentage \\
\hline \multirow[t]{3}{*}{ Age in years } & $15-24$ & 131 & 14.07 \\
\hline & $25-34$ & 484 & 51.99 \\
\hline & 35 and above & 316 & 33.94 \\
\hline \multirow[t]{2}{*}{ Residence } & Urban & 605 & 64.98 \\
\hline & Rural & 326 & 35.02 \\
\hline \multirow[t]{3}{*}{ Religion } & Orthodox & 849 & 91.19 \\
\hline & Muslim & 64 & 7.30 \\
\hline & Protestant & 18 & 1.93 \\
\hline \multirow[t]{4}{*}{ Educational status } & No formal education & 404 & 43.39 \\
\hline & Primary school & 301 & 32.33 \\
\hline & Secondary school & 138 & 14.82 \\
\hline & College and above & 88 & 9.45 \\
\hline \multirow[t]{4}{*}{ Partner educational status } & No formal education & 402 & 43.18 \\
\hline & Primary school & 257 & 27.60 \\
\hline & Secondary school & 158 & 16.97 \\
\hline & College and above & 114 & 12.24 \\
\hline \multirow[t]{3}{*}{ Partner HIV status } & Positive & 886 & 95.17 \\
\hline & Negative(discordant) & 3 & 0.32 \\
\hline & I don't.t know & 42 & 4.51 \\
\hline \multirow[t]{7}{*}{ Occupation } & Government employee & 154 & 16.54 \\
\hline & Student & 34 & 3.65 \\
\hline & Housewife & 321 & 34.48 \\
\hline & Daily laborer & 179 & 19.23 \\
\hline & Merchant & 163 & 17.51 \\
\hline & Farmer & 51 & 5.48 \\
\hline & Commercial sex worker & 29 & 3.11 \\
\hline \multirow[t]{3}{*}{ Wealth index } & Poor & 335 & 35.98 \\
\hline & Medium & 302 & 32.44 \\
\hline & Rich & 294 & 31.58 \\
\hline
\end{tabular}


Eight hundred sixty-four (92.80\%) study participants had a history of giving birth. Seven hundred three (75.51\%) women had two or more history of parity. Six hundred thirty $(72.92 \%)$ respondents had two or more live children. From the total respondents, almost all $839(90.12 \%)$ had a history of family planning use. Of the study participants, $52(5.59 \%)$ were currently pregnant. Of those women who were pregnant, 37(3.97\%) were intended and $15(1.62 \%)$ pregnancies were unintended. Forty-one (4.40\%) study participants gave birth in the last 06 weeks. Among those, 27(2.9\%) pregnancies were intended and the rest of the pregnancies, $4(0.43 \%)$ were unwanted and 10(1.07\%) were mistimed. Five hundred thirty-six $(60.98 \%)$ of the women were used at least one method of contraception and three hundred forty-three (39.02\%) of women were not used. From, non-users,133(14.29\%) women need children currently, 115(12.35\%) need children after 2 years and 95(10.20\%) didn't want more children. The majority of the women, 294(54.85\%) were used modern family planning for limiting and 237 (44.22\%) for spacing. The majority of the respondents, 328 (61.19) were used injectable, whereas 19(3.5\%) were used dual methods. Among 536 participants, who used any contraceptive, 296(55.23\%) of participants mentioned family planning units or facilities as their source of contraceptive, 195(36.38\%) of study participants were mentioned ART clinic/Chronic HIV care clinic (Table2). 
Table 2

Reproductive related factors for unmet need for modern family planning among HV positive reproductive age women on ART in South Gondar Zone, northwest, Ethiopia, 2020.

\begin{tabular}{|c|c|c|c|}
\hline Variable & Categories & Frequency & Percentage \\
\hline \multirow[t]{2}{*}{ History of giving birth } & Yes & 864 & 92.80 \\
\hline & No & 67 & 7.20 \\
\hline \multirow[t]{4}{*}{ Number of parity } & 0 & 67 & 7.20 \\
\hline & 1 & 161 & 17.29 \\
\hline & $2-4$ & 611 & 65.63 \\
\hline & 5 and more & 92 & 9.88 \\
\hline \multirow[t]{3}{*}{ Number of alive children } & $0-1$ & 234 & 27.08 \\
\hline & $2-3$ & 481 & 55.67 \\
\hline & 4 and more & 149 & 17.25 \\
\hline \multirow[t]{2}{*}{ Duration of relationship } & Up to 5 years & 54 & 80.60 \\
\hline & $>5$ years & 13 & 19.40 \\
\hline \multirow[t]{2}{*}{ Time to last sexual contact } & Up 01 month & 67 & 100.00 \\
\hline & $>01$ month & 0 & 0.00 \\
\hline \multirow[t]{2}{*}{ Current pregnancy status } & Yes & 52 & 5.59 \\
\hline & No & 879 & 94.41 \\
\hline \multirow[t]{2}{*}{ Wanted pregnancy at that time } & Yes & 37 & 3.97 \\
\hline & No & 15 & 1.62 \\
\hline \multirow[t]{2}{*}{ If No, Wanted current pregnancy at that time } & Later (mistimed pregnancy) & 7 & 0.76 \\
\hline & No more (unwanted pregnancy) & 8 & 0.86 \\
\hline \multirow[t]{2}{*}{ Ever use of FP } & Yes & 839 & 90.12 \\
\hline & No & 92 & 9.88 \\
\hline \multirow[t]{2}{*}{ Menstrual period } & $<6$ month & 869 & 98.86 \\
\hline & $\geq 6$ month & 10 & 1.14 \\
\hline \multirow[t]{2}{*}{ History of giving birth in the past 6 weeks } & Yes & 41 & 4.66 \\
\hline & No & 838 & 95.34 \\
\hline \multirow[t]{2}{*}{ Wanted last birth at that time } & Yes & 27 & 2.90 \\
\hline & No & 14 & 1.50 \\
\hline \multirow[t]{2}{*}{ If No, Wanted last birth at that time } & Wanted last birth later & 10 & 1.07 \\
\hline & Did not want last birth at all & 4 & 0.43 \\
\hline \multirow[t]{2}{*}{ Current FP taking history } & Yes & 495 & 53.17 \\
\hline & No & 343 & 36.84 \\
\hline
\end{tabular}




\begin{tabular}{|c|c|c|c|}
\hline Variable & Categories & Frequency & Percentage \\
\hline \multirow[t]{2}{*}{ Reason to use FP } & For spacing & 209 & 42.22 \\
\hline & For limiting & 286 & 57.78 \\
\hline \multirow[t]{7}{*}{ Current FP methods } & Female sterilization & 1 & 0.20 \\
\hline & IUD & 1 & 0.20 \\
\hline & Implant & 80 & 16.16 \\
\hline & Injectable & 328 & 66.22 \\
\hline & Pill & 25 & 5.05 \\
\hline & Condom alone & 41 & 8.28 \\
\hline & Male condom + other methods & 19 & 3.84 \\
\hline \multirow[t]{4}{*}{ FP receiving service(place) } & At ARV treatment units & 180 & 36.36 \\
\hline & family planning units & 276 & 55.84 \\
\hline & private clinic & 24 & 4.85 \\
\hline & Health post & 15 & 3.03 \\
\hline \multirow[t]{3}{*}{ Wants child within 2 years } & Yes & 133 & 14.29 \\
\hline & No & 198 & 21.26 \\
\hline & Unsure & 12 & 1.29 \\
\hline \multirow[t]{2}{*}{ Wants child after two years } & Later & 115 & 12.35 \\
\hline & No more children & 95 & 10.20 \\
\hline
\end{tabular}

\section{Prevalence of unmet need for modern family planning}

Unmet need for Family planning was calculated from the proportion of pregnant/amenorrheic women whose current pregnancy/ last birth was mistimed or unwanted and the proportion of fecund none pregnant women who were not using any form of family planning method but do not need any more children or want children later. The prevalence of unmet need for family planning was $25.67 \%$ with $95 \% \mathrm{Cl}(22.96-28.58), 132(14.46 \%)$ for spacing and $107(11.49)$ for limiting

\section{HIV care and related factors}

The majority of the study participants $580(62.30 \%)$ have been living with HIV for more than 5.1 years. A majority of participants, $752(80.77 \%)$ have been on ART care for 3.1 years. Among the study participants $913(98.07 \%)$ reproductive-age women, the health care provides ask about the future desire of pregnancy and give counseling for contraception during chronic HIV follow-up. A great proportion of study participants 893(95.92\%) were knowledgeable about the transmission of HIV from mother to child during pregnancy, delivery and breastfeeding. 
Table 3

HIV related factors for unmet need for modern family planning among HV positive reproductive age women on ART in South Gondar Zone, northwest, Ethiopia, 2020

\begin{tabular}{|c|c|c|c|}
\hline Variable & Categories & frequency & Percent \\
\hline \multirow[t]{2}{*}{ Duration since HIV } & 2 and below & 118 & 12.67 \\
\hline & $2.1-5$ & 233 & 25.03 \\
\hline Diagnosis (years & 5.1 and above & 580 & 62.30 \\
\hline \multirow[t]{3}{*}{ Duration on ART (years) } & 1 and below & 39 & 4.08 \\
\hline & $1.1-3$ & 140 & 15.04 \\
\hline & 3.1 and above & 752 & 80.77 \\
\hline \multirow{2}{*}{$\begin{array}{l}\text { HCP counseled for } \\
\text { contraception use }\end{array}$} & Yes & 913 & 98.07 \\
\hline & No & 18 & 1.98 \\
\hline \multirow[t]{2}{*}{ Knowledge for PMTCT } & Yes & 893 & $95.92 \%$ \\
\hline & No & 38 & $4.08 \%$ \\
\hline
\end{tabular}

\section{Reasons for not using contraceptive methods}

The most common reasons for not using contraception are $58(27.62 \%)$ fear of reaction with ART drugs, $43(20.48 \%)$

Husband/partner opposition, 47(22.38\%) fear of contraceptive side effects, 30(14.29\%) religious prohibition, and 28(13.33\%) infrequent sex (Fig. 3).

\section{Factors associated with unmet need for modern family planning among HIV positive reproductive-age women}

From eleven variables which were significant at $p$-value $<0.2$ in the bivariable logistic regression analysis (age, religion, residence, education, occupation, parity, duration on ART, ever use of family planning, wealth quantile, knowledge for PMTCT and Receiving any FP counseling), five variables(Age, education, parity, ever use of family planning and Receiving any FP counseling) were significantly associated with unmet need for modern family planning among HIV positive reproductive-age women at $p<0.05$ with $95 \%$ confidence interval (Table 4). 
Table 4

Bivariate and multivariate logistic regression analysis of unmet need for modern family planning and its explanatory variables $(n=931)$

\begin{tabular}{|c|c|c|c|c|c|}
\hline \multirow[t]{2}{*}{ Variable } & \multirow[t]{2}{*}{ Category } & \multicolumn{2}{|l|}{ Unmet need } & \multicolumn{2}{|l|}{ OR } \\
\hline & & Yes N (\%) & No N (\%) & $\operatorname{coR}(95 \% \mathrm{Cl})$ & $\mathrm{AOR}(95 \% \mathrm{Cl})$ \\
\hline \multirow[t]{3}{*}{ Age } & $15-24$ & $14(1.50)$ & $117(12.57)$ & 1 & 1 \\
\hline & $25-34$ & $91(9.77)$ & $393(42.21)$ & $1.9(1.06-3.52)$ & $1.9(0.84-4.17)$ \\
\hline & 35 and above & 134(14.39) & 182(19.55) & $\begin{array}{l}\text { 6.2(3.39- } \\
11.18)\end{array}$ & $\begin{array}{l}6.5(2.86- \\
14.66)^{\star *}\end{array}$ \\
\hline \multirow[t]{3}{*}{ Religion } & Orthodox & $211(22.66)$ & $638(68.53)$ & 1 & 1 \\
\hline & Muslim & $19(2.04)$ & $45(4.83)$ & $\begin{array}{l}1.28(0.73- \\
2.23)\end{array}$ & $1.4(0.74-2.59)$ \\
\hline & Protestant & $9(0.97)$ & $9(0.97)$ & $3.02(1.18-7.72$ & $3.0(0.99-9.12)$ \\
\hline \multirow[t]{4}{*}{ Educational status } & No formal Education & 118(12.67) & 286(30.72) & $\begin{array}{l}1.40(0.82- \\
2.41)\end{array}$ & $0.4(0.19-1.06)$ \\
\hline & Primary (1-8) & $86(9.24)$ & 215(23.09) & $\begin{array}{l}1.36(0.78- \\
2.38)\end{array}$ & $0.6(0.27-1.34)$ \\
\hline & Secondary (9-12) & $15(1.61)$ & $123(13.21)$ & $\begin{array}{l}0.41(0.19- \\
0.86)\end{array}$ & $\begin{array}{l}0.25(0.10- \\
0.61)^{\star}\end{array}$ \\
\hline & College and above & $20(2.15)$ & $68(7.30)$ & 1 & 1 \\
\hline \multirow[t]{7}{*}{ Occupation } & $\begin{array}{l}\text { Government } \\
\text { Employee }\end{array}$ & $27(2.9)$ & $127(13.64)$ & 1 & 1 \\
\hline & Student & $7(0.75)$ & $27(2.90)$ & $\begin{array}{l}1.22(0.48- \\
3.09)\end{array}$ & $3.5(0.93-12.91)$ \\
\hline & Housewife & $85(9.13)$ & $236(25.35)$ & $\begin{array}{l}1.69(1.04- \\
2.75)\end{array}$ & $1.3(0.66-2.75)$ \\
\hline & Daily laborer & $57(6.12)$ & $122(13.10)$ & $\begin{array}{l}2.20(1.30- \\
3.70)\end{array}$ & $2.1(0.99-4.43)$ \\
\hline & Merchant & $44(4.73)$ & 119(12.78) & $\begin{array}{l}1.74(1.01- \\
2.98)\end{array}$ & $1.7(0.83-3.49)$ \\
\hline & Farmer & $15(1.61)$ & $36(3.87)$ & $\begin{array}{l}1.96(0.94- \\
4.07)\end{array}$ & $0.78(0.29-2.17)$ \\
\hline & $\begin{array}{l}\text { Commercial sex } \\
\text { worker }\end{array}$ & $4(0.43)$ & $25(2.69)$ & $\begin{array}{l}0.75(0.24- \\
2.34)\end{array}$ & $0.91(0.24-3.46)$ \\
\hline \multirow[t]{4}{*}{ Parity } & 0 & $14(1.51)$ & $52(5.59)$ & 1 & 1 \\
\hline & 1 & $35(3.76)$ & 126(13.55) & $\begin{array}{l}1.03(0.51- \\
2.07)\end{array}$ & $2.1(0.93-4.79)$ \\
\hline & $2-4$ & 143(15.38) & 468(50.32) & $\begin{array}{l}1.13(0.61- \\
2.12)\end{array}$ & $1.9(0.89-4.16)$ \\
\hline & 5 and above & $47(5.05)$ & $45(4.84)$ & $\begin{array}{l}3.88(1.89- \\
7.95)\end{array}$ & $\begin{array}{l}5.1(2.08- \\
12.43)^{\star \star}\end{array}$ \\
\hline
\end{tabular}




\begin{tabular}{|c|c|c|c|c|c|}
\hline \multirow[t]{3}{*}{ Duration on ART (years) } & 1 and below & $10(1.07)$ & $29(3.11)$ & $\begin{array}{l}0.92(0.44- \\
1.93)\end{array}$ & $1.4(0.57-3.57)$ \\
\hline & $1.1-3$ yrs. & $25(2.69)$ & $115(12.35)$ & $\begin{array}{l}0.58(0.37- \\
0.93)\end{array}$ & $0.97(0.57-1.66)$ \\
\hline & 3.1 and above & 204(21.91) & $548(58.86)$ & 1 & 1 \\
\hline \multirow[t]{2}{*}{ Ever use FP } & Yes & 190(20.41) & 649(69.71) & 1 & 1 \\
\hline & No & $49(5.26)$ & $43(4.62)$ & $\begin{array}{l}3.89(2.50- \\
6.05)\end{array}$ & $\begin{array}{l}3.9(2.28- \\
6.67)^{* *}\end{array}$ \\
\hline \multirow[t]{3}{*}{ Wealth quantile } & Poor & 103(11.06) & 232(24.92) & $\begin{array}{l}1.39(0.98- \\
1.98)\end{array}$ & $1.0(0.66-1.67)$ \\
\hline & Medium & $65(6.98)$ & $237(25.46)$ & $\begin{array}{l}0.86(0.59- \\
1.26)\end{array}$ & $0.83(0.54-1.29)$ \\
\hline & Rich & 71(7.63 & $223(23.95)$ & 1 & 1 \\
\hline \multirow{2}{*}{$\begin{array}{l}\text { Receiving any FP } \\
\text { counselling }\end{array}$} & Yes & 217(23.31) & $676(72.61)$ & 1 & 1 \\
\hline & No & $22(2.36)$ & $16(1.72)$ & $\begin{array}{l}6.04(2.24- \\
16.29)\end{array}$ & $\begin{array}{l}4.2(1.91- \\
9.37)^{\star *}\end{array}$ \\
\hline \multirow[t]{2}{*}{ Knowledge for PMTCT } & Yes & $224(24.06)$ & $669(71.86)$ & 1 & 1 \\
\hline & No & 15(1.61) & $23(2.47)$ & $\begin{array}{l}1.96(0.99- \\
3.79)\end{array}$ & $0.96(0.43-2.14)$ \\
\hline
\end{tabular}

In the multivariable analysis, the odds of having unmet need among women in the age group of 35-49 years was 6.5 times higher as compared with women in the age group of $15-24$ years $(A O R=6.5,95 \% \mathrm{Cl}=2.86-14.66)$. The odds of unmet need for family planning among women with secondary educational status (9-12) was reduced by $75 \%$ compared to women who have college and above educational status $(A O R=0.25,95 \% \mathrm{Cl}=0.10-0.61)$. The odds of unmet need for family planning among women who do not ever use contraception was 3.9 times higher than those who ever used contraception $(A O R=3.9$, $95 \% \mathrm{Cl}=2.28-6.67)$. The odds of unmet need for family planning among women who had five and above parity was 5.1 times higher than those women who had none parity $(A O R=5.1,95 \% \mathrm{Cl}=2.08-12.43)$. The odds of unmet need for family planning among women who are not counseled about contraception during HIV follow-up was 4.2 times higher than those women who were counseled about contraception (AOR $=4.2,95 \% \mathrm{Cl}=1.91-9.37)$.

\section{Discussion}

This study assessed the prevalence of unmet need for modern family planning methods and associated factors among HIVpositive reproductive age women. The prevalence of unmet need for modern family planning among study participants was $25.67 \%(95 \% \mathrm{Cl}=22.96-28.58)$ of which $132(14.46 \%)$ was for spacing and107 $(11.49 \%)$ for limiting.

In this study, 25.67\% reproductive age women had unmet need for modern family planning methods. This finding was in line with the findings from studies in Ghana (27.8\%)(32) and Addis Ababa, Ethiopia (25.1\%)(19). However, this finding was lower than study findings from South Africa (58.8\%)(33), Nigeria (64.9\%)(12) and Amhara regional state, Ethiopia (35.3\%)(34).The reason for this discrepancy might be using a different study design(prospective cohort study), and unmet need definition, in study conducted South Africa, study participants with 12 month postpartum period and age restriction(18-35)years were considered(33), in study conducted in Nigeria were not used the revised definition for estimation of unmet need for contraception (31). In addition to this, high HIV prevalence among adults in sub-Saharan Africa may have contributed to a 
higher unmet need for family planning (35). The discrepancy in the study from the Amhara region might be, the previous study focuses on only women who give birth between 06 weeks to 24 months and pregnant mothers were excluded from the study. Mother on PMTCT not taking family planning due to less perception to pregnancy since breastfeeding and no menses return since last birth $(19,36,37)$.

In contrast, the finding of the current study was higher than study findings from India (17\%)(38), Zimbabwe(19\%)(39), Nigeria (20\%) (40), Hawassa, Ethiopia (19.1\%) (21), and Nekemte, western, Ethiopia (15.4\%) (20). This discrepancy might be due to the sample size difference. The sample size of a study done in India was four times less than the current study sample size. In a study done in Zimbabwe, the participants were mothers on PMTCT(9-18 months) and different study designs (39). In a study done in Nigeria, pregnant mothers were excluded (40). In a study done in a different area of Ethiopia, the discrepancy might be due to the different health service provision and different characteristic of study participants (41) or this difference might be explained by the different distribution of PLHIV per region, 30\% in Amhara, 26\% in Oromia and $9 \%$ in Southern Nations, Nationalities, and Peoples' Region (42). unmet need for family planning in the general population as reported in the report of EDHS 2016 was (22\%) (4). This discrepancy might be due to different study populations.

In the multivariable analysis, the unmet need for contraception was higher among old reproductive-age women. This finding was supported by study findings from rural Uganda (43), Nigeria (44, 45), Togo (46), and Ethiopia (20). This might be as the age of the women increases the risk of pregnancy will decrease $(19,47)$. It may be due to opposition to use contraception by partners, fears of contraception side effects, health concerns, the previous negative experience of using contraception and using family planning may interfere with sexual pleasure $(19,36,48)$.

Another factor affecting the unmet need for family planning was educational status. Education was the most important factor in increasing contraceptive knowledge to plan the desire to limit or space births. In our study, women with educational status of $(9-12)$ have a $75 \%$ lower risk of unmet need for family planning. This finding was contradicting with findings from Nigeria (40), Botswana (49) and western Ethiopia (20), which reports, women with no formal education and primary education had a higher prevalence of unmet need than those collages and above educational status. According to demographic health survey analytical studies, the relationship between education and unmet need for family planning was not constant across countries (31). In democratic Congo in 2007 as education increase, the unmet need for family planning also increases (CDHS,2007). But it needs further study focusing on the effect of education on unmet needs.

Ever use of contraception was also a significant factor affecting the unmet need for family planning. Women who didn't ever use had higher unmet need than those who had ever used. This finding was supported by study findings from Federal Teaching Hospital Gombe, Nigeria (50), Hawassa, Ethiopia (21) and Gondar town, Ethiopia (51). This might be women on ART, contraception use may feel exacerbation of HIV disease progression (51). This might be due to a lack of awareness for contraception or fear of contraceptive side effects and heard miss information from previously experienced mothers leads to frustration (52). Previous use of family planning increases knowledge and decrease fear of family planning side effects.

Women who had five and above parity had a higher unmet need for family planning than those women who had none parity. This finding consistent with studies done in Nigeria (50) and Northern Uganda (53). This might be due to women who had none or one child want a child soon no need of limiting and spacing or may have the desire of more children $(19,54)$ and Multiparous mother may achieve desired family size. This might be as women have more children, the unmet need for spacing births tends to decrease, but the unmet need for limiting increases (31).

Counseling about contraception also affects the unmet need for family planning.

Women who were not counseled about contraception during HIV follow-up had a higher unmet need for family planning than those women who were counseled. This finding was consistent with Uganda and Ethiopia $(19,55)$. The possible explanation could be family planning counseling during ART follow up can create awareness and increase knowledge to use 
contraception and improving information about their risk of becoming pregnant and about the choices of contraception(36, $56)$.

\section{Limitation Of The Study}

As the study included more sensitive issues, social desirability bias could not be ruled out. Consequently, some women accessing the ART services may report higher use of condoms and other contraceptive methods. Similarly, women may report a birth or current pregnancy as wanted once the child is born. This can result in an underestimation of the true extent of unwanted births and unmet needs.

\section{Conclusion}

The unmet need for modern family planning among HIV positive reproductive age married/union women was very high. Unmet need for family planning is mainly influenced by age (35-49), education (9-12), having no experience of contraception use, having five and above parity, and no counseling for contraception. Therefore, family planning programs need to give focus on old age (35-49 years) reproductive-age women, multipara women and not ever used contraception. Health care provider needs to be focus patient-centered counseling to create awareness on the benefits of contraception in the settings of HIV infection.

\section{Abbreviations}

AIDS: Acquired Immune Deficiency Syndrome; AOR: Adjusted Odd Ratio; ART: Anti-retroviral therapy; COR: Crude Odd ratio; EDHS: Ethiopian demographic health survey; FP: Family Planning; HIV: Human Immune Virus; PLHIV: People Living Human Immune Virus; PMTCT: Prevention of Mother to Child Transmission; STI: Sexual Transmitted Infection; WHLHIV: Women Living with Human Immune Virus; WHO: World Health Organization

\section{Declarations}

\section{Ethical considerations}

Ethical clearance was obtained from the Institutional Review Board of the University of Gondar, College of Medicine and Health Sciences, Institute of public health with letter number of Ref No/IPH/837/6/2012. Support letter and permission was obtained from Amhara Regional Health Bureau and from South Gondar health zonal health department to the concerned bodies. Health facilities were approached with a formal letter written to the ward team leader. All the study participants were well informed about the benefit of the study along with their right to refuse before proceeding with the questions. Consent was obtained from each participant before starting the interview. Moreover, the confidentiality of the information was kept without the participant's name and ID. Data was not disclosed to any person other than the principal investigator.

\section{Consent to publication}

Not applicable outside of the researcher has access to any of the information collected.

\section{Availability of data and materials}

Data will be available upon reasonable request from the corresponding author

\section{Competing Interests}

No competing interest

\section{Funding}


This study was funded by self (Principal investigator).

\section{Authors contribution}

MA conceived the study, developed the tool, coordinated the data collection activity, and carried out the statistical analysis. MMB and AT participated in the design of the study and development of the tool, performed the statistical analysis, and drafted the manuscript. All authors read and approved the final manuscript.

\section{Acknowledgment}

We would like to provide our profound thanks to the University of Gondar for support and to secure the ethical clearance to conduct this study. The authors acknowledge the data collectors, supervisees who were involved in this study. Finally, we thank the study participants involved in this study.

\section{References}

1. WHO. contraception fact sheet. Available:https://www.who.int/en/news-room/fact-sheets/detail/family-planningcontraception. 2019/2020.

2. Kantorová V, Wheldon MC, Ueffing P, Dasgupta AN. Estimating progress towards meeting women's contraceptive needs in 185 countries: A Bayesian hierarchical modelling study. PLoS medicine. 2020;17(2):e1003026.

3. United Nations DoEaSA, Population Division. New York: United Nations. Family Planning and the 2030 Agenda for Sustainable Development. Available https://www.un.org/en/development/desa/population/publications/pdf/family/familyPlanning_DataBooklet_2019.pdf.

4. Central Statistical Agency CSAE, Icf. Ethiopia Demographic and Health Survey 2016. Addis Ababa, Ethiopia: CSA and ICF; 2017.

5. Halperin DT, Stover J, Reynolds HWJA. Benefits and costs of expanding access to family planning programs to women living with HIV. 2009;23:S123-S30.

6. Cleland J, Bernstein S, Ezeh A, Faundes A, Glasier A, Innis JJTL. Family planning: the unfinished agenda. 2006;368(9549):1810-27.

7. Reynolds HW, Janowitz B, Homan R, Johnson LJStd. The value of contraception to prevent perinatal HIV transmission. 2006;33(6):350-6.

8. Reynolds HW, Janowitz B, Wilcher R, Cates WJSti. Contraception to prevent HIV-positive births: current contribution and potential cost savings in PEPFAR countries. 2008;84(Suppl 2):ii49-ii53.

9. UNAIDS SF, Stay Free, AIDS Free targets,2020 report,. Avilable :https://www.unaids.org/sites/default/files/media_asset/start-free-stay-free-aids-free-2020-progress-report_en.pdf. 2020.

10. Wilcher R, Cates WHO. Reproductive choices for women with HIV. 2009;87:833-9.

11. UNAIDS. progress report on the global plan towards the elimination of new HIV infections among children by 2015 and keeping their mothers alive. 2013.

12. Shehu A, Joshua I, Umar Z, Lawal A. Non-Use of Contraceptive by Human Immunodeficiency Virus Positive Women Attending Anti-Retroviral Clinics in Zaria, Nigeria. 2019;1(1):74-9.

13. Singh S, Darroch JE. Adding it up: Costs and benefits of contraceptive services. Estimates for 2012. 2012.

14. Aliyu AA. Family Planning Services in Africa: The Successes and Challenges. 2018:69.

15. Todd CS, Anderman TC, Long S, Myer L, Bekker LG, Petro GA, et al. A systematic review of contraceptive continuation among women living with HIV. Contraception. 2018;98(1):8-24. 
16. Ezugwu EC, lyoke CA, Nkwo PO, Ezegwui HU, Akabueze JC, Agu PU. Unintended pregnancy among HIV-positive pregnant women in Enugu, southeast Nigeria. International Journal of Gynecology \& Obstetrics. 2016;132(1):60-3.

17. Feyissa TR, Harris ML, Melka AS, Loxton D. Unintended Pregnancy in Women Living with HIV in Sub-Saharan Africa: A Systematic Review and Meta-analysis. AIDS and behavior. 2019;23(6):1431-51.

18. Yotebieng M, Norris A, Chalachala JL, Matumona Y, Ramadhani HO, Behets FJTPAmj. Fertility desires, unmet need for family planning, and unwanted pregnancies among HIV-infected women in care in Kinshasa, DR Congo. 2015;20.

19. Abubeker FA, Fanta MB, Dalton VK. Unmet Need for Contraception among HIV-Positive Women Attending HIV Care and Treatment Service at Saint Paul's Hospital Millennium Medical College, Addis Ababa, Ethiopia. 2019;2019.

20. Feyissa T, Melka A. Demand for modern family planning among married women living with HIV in Western Ethiopia. Plos one. 2014;9.

21. Feyssa MD, Tsehay YB, Tadesse AW. Unmet need for family planning among women in HIV At Antiretroviral Treatment Clinic in South Ethiopia: A Challenge to Prevention of Mother to Child Transmission. . 2015;6(469):2.

22. Dugg P, Chhabra P, Sharma AK. Contraceptive use and unmet need for family planning among HIV-positive women: A hospital-based study. Indian journal of public health. 2020;64(1):32-8.

23. World Health Organization and Johns Hopkins Bloomberg School of Public Health. Family Planning: A Global Handbook for Providers. 2018.

24. Damian DJ, George JM, Martin E, Temba B, Msuya SEJC, medicine r. Prevalence and factors influencing modern contraceptive use among HIV-positive women in Kilimanjaro region, northern Tanzania. 2018;3(1):7.

25. WHO. Guidance on global scale-up of the prevention of mother to child transmission of HIV: towards universal access for women, infants and young children and eliminating HIV and AIDS among children. 2007.

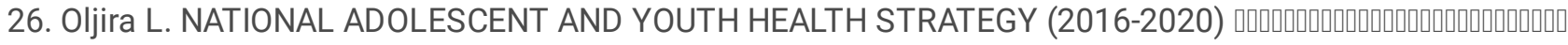
Q

27. WHO. Strategic Vision 2010-2015: Preventing mother-to-child transmission of HIV to reach the UNGASS and millennium development goals. Geneva: WHO Press; 2011.

28. Feyissa TR, Melka ASJPo. Demand for modern family planning among married women living with HIV in western Ethiopia. 2014;9(11):e113008.

29. Central Statistical Agency of Ethiopia (CSA). Ethiopian population census,Amhara region.Available:https://en.wikipedia.org/wiki/Amhara_Region\#:\%2012.27\%25\%20of\%20the\%20population.; 2007.

30. south gondar HIV/AIDS prevention and control office report. 2019.

31. Bradley SEK, Croft TN, Fishel JD, Westo CF. Revising unmet need for family planning. DHS Analytical Studies No 25 2012.

32. Laryea DO, Amoako YA, Spangenberg K, Frimpong E, Kyei-Ansong JJBwsh. Contraceptive use and unmet need for family planning among HIV positive women on antiretroviral therapy in Kumasi, Ghana. 2014;14(1):126.

33. Rucinski KB, Powers KA, Schwartz SR, Pence BW, Chi BH, Black V, et al. Longitudinal patterns of unmet need for contraception among women living with HIV on antiretroviral therapy in South Africa. PLoS One. 2018;13(12):0209114.

34. Zewdie Z, Yitayal M, Kebede Y, Gebeyehu A. Status of family planning integration to HIV care in Amhara regional state, Ethiopia. BMC pregnancy and childbirth. 2020;20(1):145.

35. Global HIV \& AIDS statistics - 2020 fact sheet estimate countries Available https://www.unaids.org/en/resources/factsheet.

36. Sedgh G, Ashford LS, Hussain. Unmet need for contraception in developing countries: examining women's reasons for not using a method. New York: Guttmacher Institute. 2016;2:2015-6.

37. Tadele A, Abebaw D, Ali R. Predictors of unmet need for family planning among all women of reproductive age in Ethiopia. Contracept Reprod Med. 2019;4:6. 
38. Dugg P, Chhabra P, Sharma AKJIJoPH. Contraceptive use and unmet need for family planning among HIV-positive women: A hospital-based study. 2020;64(1):32.

39. McCoy SI, Buzdugan R, Ralph LJ, Mushavi A, Mahomva A, Hakobyan A, et al. Unmet need for family planning, contraceptive failure, and unintended pregnancy among HIV-infected and HIV-uninfected women in Zimbabwe. 2014;9(8):e105320.

40. Okunola TO, ljaduola KT, Adejuyigbe EA. Unmet need for contraception among HIV-positive women in Ile-Ife, Nigeria. Trop Doct. 2019;49(1):26-31.

41. Woldemichael A, Takian A, Sari AA, Olyaeemanesh AJPo. Availability and inequality in accessibility of health centrebased primary healthcare in Ethiopia. 2019;14(3).

42. Federal HIV/AIDS Prevention and Control Office. HIV Prevention in EthiopiaNational Road Map2018 - 2020.

43. Jhangri GS, Heys J, Alibhai A, Rubaale T, Kipp W. Unmet need for effective family planning in HIV-infected individuals: results from a survey in rural Uganda. 2012;38(1):23-9.

44. Okigbo CC, McCarraher DR, Chen M, Gwarzo U, Vance G, Chabikuli OJAjorh. Unmet need for contraception among clients of FP/HIV integrated services in Nigeria: the role of partner opposition. 2014;18(2):134-43.

45. Mohammed A, Chiroma D, Laima C, Danimoh M, Odunze. Predictors of Unmet Need for Family Planning among HIV Positive Women in Care in Federal Teaching Hospital Gombe, Nigeria. PA \%J Asian Journal of Medicine. 2020:26-33.

46. Yaya I, Nambiema A, Dieng S, Djalogue L, Agboyibor MK, N'Dri MK, et al. Factors associated with unmet need for limiting childbirth among women living with HIV in Togo: An averaging approach. 2020;15(5):e0233136.

47. Wanyenze R, Matovu J, Kamya M, Tumwesigye N, Nannyonga M, Wagner G. Fertility desires and unmet need for family planning among HIV infected individuals in two HIV clinics with differing models of family planning service delivery. BMC Womens Health. 2015;15(5):1-12.

48. Wekesa E, Coast E. Contraceptive need and use among individuals with HIV/AIDS living inthe slums of Nairobi, Kenya. 2015.

49. Letamo G, Navaneetham KJBo. Levels, trends and reasons for unmet need for family planning among married women in Botswana: a cross-sectional study. 2015;5(3):e006603.

50. Mohammed A, Chiroma D, Laima C, Danimoh M, Odunze PJ. Predictors of Unmet Need for Family Planning among HIV Positive Women in Care in Federal Teaching Hospital Gombe, Nigeria. 2020;Asian Journal of Medicine Health:26-33.

51. Handebo S, Kassie M, Habitu Y. One in every four women living with HIV had unmet need for family planning in Gondar city, Northwest Ethiopia: Cross-sectional study. 2019.

52. Kebede YB, Geremew TT, Mehretie Y, Abejie AN, Bewket L, Dellie E. Associated factors of modern contraceptive use among women infected with human immunodeficiency virus in Enemay District, Northwest Ethiopia: a facility-based cross-sectional study. BMC public health. 2019;19(1):1584.

53. Bongomin F, Chelangat M, Eriatu A, Chan Onen B, Cheputyo P, Godmercy SA, et al. Prevalence and factors associated with contraceptive use among HIV-infected women of reproductive age attending infectious disease clinic at Gulu Regional Referral Hospital, Northern Uganda. 2018;2018.

54. Wanyenze RK, Matovu JK, Kamya MR, Tumwesigye NM, Nannyonga M, Wagner GJJBwsh. Fertility desires and unmet need for family planning among HIV infected individuals in two HIV clinics with differing models of family planning service delivery. 2015;15(1):5.

55. Nabirye J, Matovu JK, Bwanika JB, Makumbi F, Wanyenze RKJBWsH. Missed opportunities for family planning counselling among HIV-positive women receiving HIV Care in Uganda. 2020;20:1-12.

56. Cleland J, Harbison S, Shah IHJSifp. Unmet need for contraception: issues and challenges. 2014;45(2):105-22.

\section{Figures}

Page 17/19 


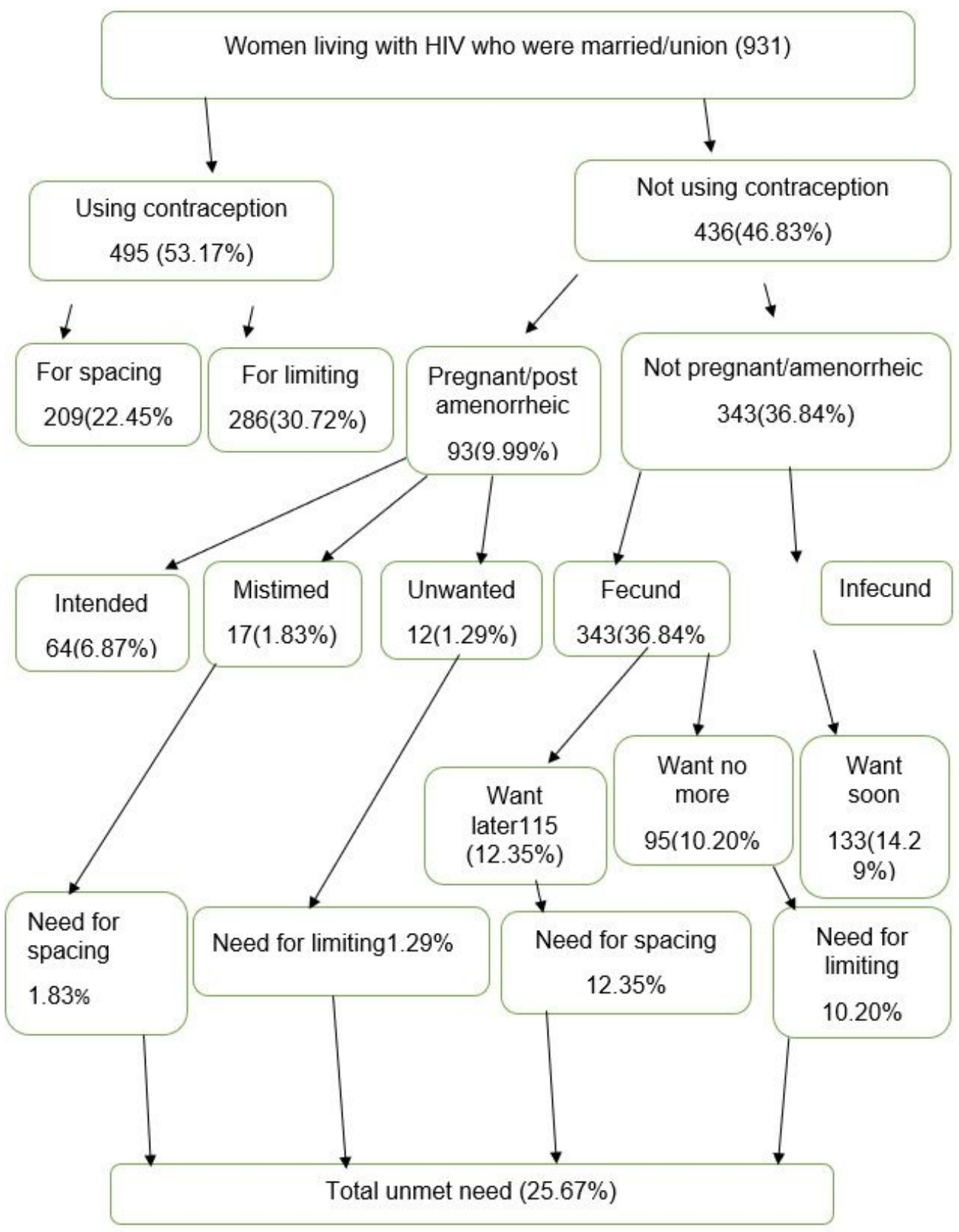

Figure 1

total unmet need for modern family planning among married/union women living with HIV in South Gondar, Ethiopia, 2020 


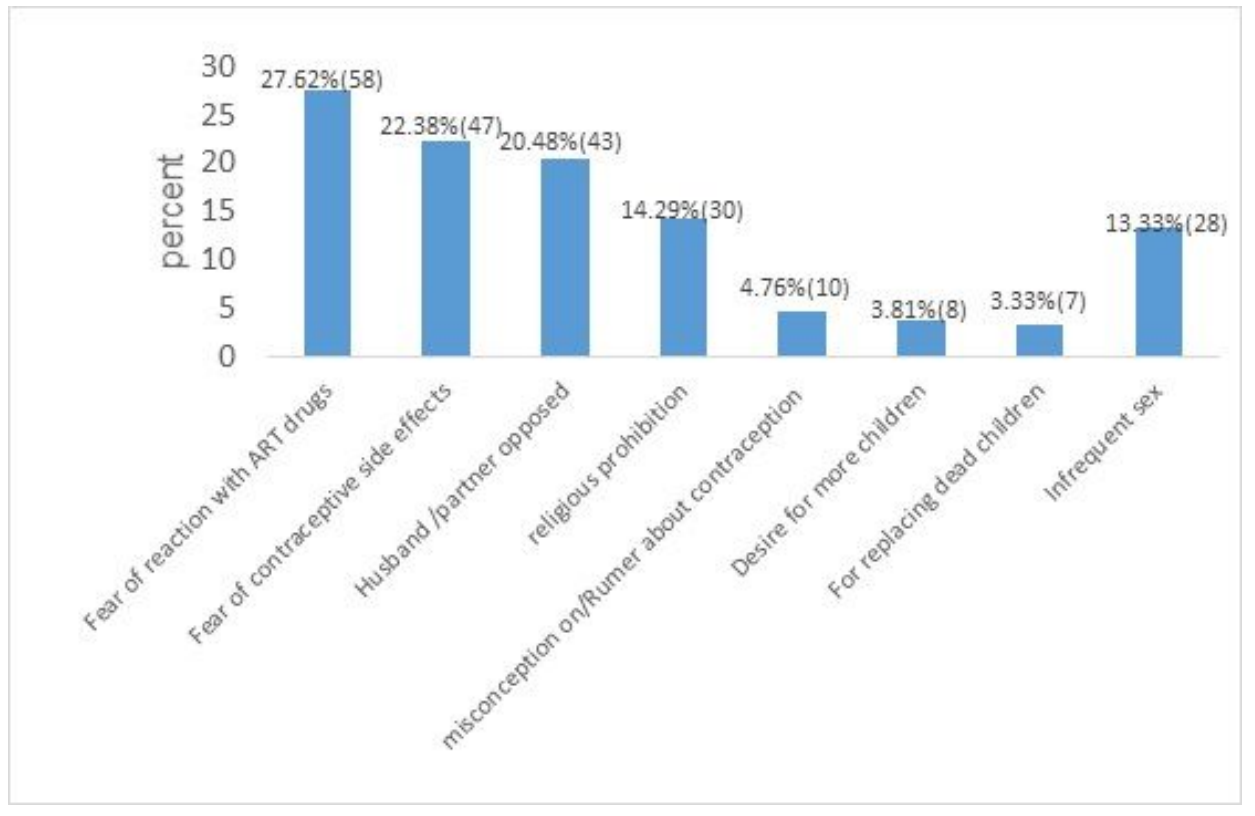

Figure 2

Reason for the not using contraception, South Gondar, Ethiopia, 2020 